\title{
İktisat Okullarında Piyasa Başarısızlıkları ve Finansal Kriz Yaklaşımı: Türkiye'de 2001 Finansal Krizi Üzerine Post Keynesyen Bir Analiz
}

\section{Market Failures In Economic Schools and Financial Crisis Approach: A Post Keynesian Analysis On The 2001 Financial Crisis In Turkey}

Ömer Tuğsal Doruk ${ }^{a^{*}}$

${ }^{a}$ Dr., Kıbrıs Amerikan Üniversitesi, Lefkoşa/KKTC

ORCID: 0000-0002-2382-1042

\section{MAKALE BILGİSI}

\section{Makale Geçmişi:}

Başvuru tarihi: 23 Eylül 2018

Düzeltme tarihi: 03 Kasım 2018

Kabul tarihi: 27 Kasım 2018

Anahtar Kelimeler:

Finansal Kriz

Piyasa başarısızlıkları

Karşılaştırmalı Finansal Kriz Analizi

Türkiye 2001 Finansal Krizi

\section{ARTICLE INFO}

\section{Article history:}

Received 23 September 2018

Received in revised form 03 November 2018

Accepted 27 November 2018

\section{Keywords:}

Financial crisis

Market failures

Comparative financial crisis analysis

The Turkish 2001 financial Crisis

\section{ÖZ}

Finansal kriz yaklaşımı, makro iktisadi analizde iktisat okulları tarafından farklı varsayımlara dayanmaktadır. Bu çalışmada finansal kriz yaklaşımı, Post Keynesyen iktisat okulu çerçevesinde Türkiye ekonomisinde yaşanan en ağır finansal krizlerden birisi olan 2001 finansal krizi açısından karşılaştırmalı olarak incelenmektedir. Genel itibariyle Post Keynesyen iktisat okulunun Türkiye ekonomisinde 2001 finansal krizini açıklamada alternatif bir yaklaşıma sahip olduğu ve krizin ana nedenlerini daha iyi açıkladığı görülmektedir.

\section{Giriş}

Makro iktisadi analizde finansal kriz yaklaşımı, finansal krizlerin yaşandığı dönemlerde oldukça ilgi çeken ve aynı zamanda literatürde üzerinde uzlaşı olmayan bir konu olma özelliğindedir. 1970'li yıllarda yaşanan petrol krizleri sırasında yaşanan stagflasyon sorununa Keynesyen reçeteler ile çözüm bulunamaması üzerine Yeni Klasik iktisat okulunun ana önermeleri eşliğinde a priori finansal kriz yaklaşımı benimsenmiştir. 1970'li yılları takip eden süreçte baskın olan arz yanlı politikaların etkisiyle finansal piyasalarda deregülasyonların tercih edilmesi de Yeni Klasik iktisat okulunun finansal kriz yaklaşımının benimsendiğini göstermektedir.

1970'li y1llardan itibaren makroiktisadi analizde başlayan dönüşüm beraberinde finansal kriz ve finansal krizlere neden olan piyasa başarısızlıklarına karşı olan yaklaşımları ve varsayımları da bu dönüşüm etrafında şekillendirmiştir. Keynesyen politikaların stagflasyona çözüm sunamaması üzerine Keynesyen iktisatta Yeni Keynesyen ve Post Keynesyen ayrımı, Yeni Klasiklerin varsayımlarının giderek

\footnotetext{
* Sorumlu yazar/Corresponding author

e-posta: o.doruk@auc.edu.tr
} 
ön plana alınmasına neden olmuștur. Ancak 2008 finansal krizi ile birlikte makro iktisadi analiz ve finansal kriz ilișkisi tekrar gündeme gelmiştir. Lavoie (2016) 2008 finansal krizinin tahmin edilmesinde ve krizin oluşum aşamasına ilișkin olarak makroiktisadın da kendi içerisinde bir kriz yaşadığını belirtmektedir.

Çalışmada 2001 finansal krizi Post Keynesyen iktisat yaklaşımı ile Türkiye ekonomisi açısından özgün bir çerçevede ele alınırken Post Keynesyen iktisadın finansal kriz yaklaşımı da Yeni Klasik iktisat ve Yeni Keynesyen iktisat okulları ile karşılaştırmalı olarak analiz edilmektedir. Bu noktada Türkiye'de yaşanan 2001 finansal krizinin farklı açılardan ele alınması, çalışmanın kendine özgün bir yaklaşıma sahip olduğunu göstermektedir. Çalışmanın bu açıdan Türkiye eksenli finansal kriz literatürüne zengin bir katkıda bulunması hedeflenmektedir.

Çalışmanın ikinci bölümünde finansal kriz yaklaşımları Yeni Keynesyen, Yeni Klasik ve Post Keynesyen iktisat okulları çerçevesinde incelenmektedir. Çalışmanın üçüncü bölümünde ise Türkiye'de yaşanılan 2001 finansal krizinin altında yatan etkenler Post Keynesyen çerçevede incelenmektedir. Çalışmanın dördüncü ve son bölümünde ise; genel çıkarımlar yer almaktadir.

\section{Finansal Kriz Yaklaşımları}

\subsection{Yeni Klasiklerde Finansal Kriz Yaklaşımı}

Yeni Klasik iktisat okulunun finansal krizlere yaklaşımının temelinde piyasa düzenini bozan dışsal şoklar yer almaktadır. Yeni Klasik iktisat okulunda piyasaların serbest bırakılması yaklaşımı baskındır (laissez faire yaklaşımı). Piyasa düzenini bozucu herhangi bir dışsal şok durumunda piyasanın kendi dengesine geleceği belirtilmektedir. Diğer bir deyişle Yeni Klasik iktisat okulunda finansal krizler tamamen rastlantısal bir olgu olma özelliğindedir.

Ortodoks ya da ana akım paradigma olarak da adlandırılan Yeni Klasik iktisat okulunda kriz yaklaşımı, krizlerin 'rastlantısal' ve konjonktürel olaylar olarak nitelendirilmesine dayanmaktadır. Yeni Klasik iktisatçılar, krizlerin oluşumu açısından rasyonel beklentiler teorisi çerçevesinde oluşan kararlarda dinamikleri bozan dışsal şokların ve görünmez el mekanizmasında piyasaya olan dişsal (çoğunlukla devlet müdahalesine bağlı olan) şokların piyasa dinamiklerinin bozması üzerinde durmaktadır (Keen, 2013). Yeni Klasik iktisatçılar, piyasa başarısılıklarının dışsal olduğu ve devletin gerekli (ya da zorunlu) olmadıkça piyasaya müdahale etmediği bir yaklaşımı savunmaktadır.

Yeni Klasik iktisat okulunda aynı zamanda Klasik Dikotomi’nin yeri oldukça önemlidir (Romer, 1993).Klasik Dikotomi, parasal faktörlerin kısa vadede reel faktörleri etkileyebilmesi ancak uzun vadede reel faktörler üzerine bir etkide bulanamayacağı varsayımı olarak tanımlanmaktadır (Romer, 1993).Dolayısıyla, Yeni Klasik makro iktisadi analizde paranın yansızlığı oldukça önemli bir yer tutmaktadır. Klasik Dikotomi, tam bilgi dağılımı ve rasyonel bireyler ile finansal krizlere yaklaşımın ana öğelerini oluşturmaktadır. Yeni Klasik iktisatta bu varsayımlar altında finansal krizler sadece rastlantisal olgular olmaktadir. Örneğin, kısa vadede para yanılsamasına sahip olan bireyler, rasyonel birey ve bilginin tam dağılımı varsayımları altında kısa vadeli bu yanılsamanın farkına vararak, uzun vadede bu şoku piyasa dinamikleri vasıtasıyla giderecek yapıdadır. Johnson vd. (2001: 409)'ne göre Klasik Dikotomi'de istihdam düzeyi ve çıktı düzeyi reel faktörler tarafindan belirlenirken, enflasyonun parasal faktörler tarafından belirlendiğinin altını çizmektedir. Aynı zamanda tam rekabet piyasası, piyasaların temizlendiği fiyat düzeyi varsayımı (maket clearing) ve piyasaların tam istihdam düzeyinde çalışması Klasik Dikotomi'nin önemli varsayımlarıdır. Bu noktada ana akım iktisatta Klasik Dikotomi'nin önemli bir yer tuttuğu görülmektedir. Yeni Klasik iktisatçıların finansal krize rastlantısal ve dişsal olarak yaklaşmasının arkasında Klasik Dikotomi’nin önemli bir payı bulunmaktadır.

\subsection{Yeni Keynesyen İktisatta Finansal Kriz Yaklaşımı}

1970'li y1llarda Keynesyen doktrine olan güven kaybı, Keynesyen iktisatçılar cephesinde huzursuzluk yaratmış ve Keynesyen kanatta ayrılmalara neden olmuştur. Keynesyen doktrin; Keynes'in görüşlerini devam ettirmeye yönelik paradigmayı destekleyen Post Keynesyen İktisat Okulu ve Keynesyen Doktrini yeni bir kulvarda farklı eklentiler ile harmanlayan Yeni Keynesyen İktisat Okulu olarak ikiye ayrılmıştır. Keynesyen kanadın modern temsilcilerinden biri olan Yeni Keynesyen iktisat okulunda finansal krizler, piyasadaki yetersizlikler ve eksikliklerden kaynaklanmaktadır.

Yeni Keynesyen iktisatta piyasa başarısızlıklarından birisi olan asimetrik enformasyon sorunsalı, bu soruna dayalı ters seçim, ahlaki risk, sürü psikolojisi gibi piyasa başarısızlıkları politika seçim sorunlarından kaynaklanabilmektedir. Bu sorunların temelinde piyasalardan kaynaklı yapısal sorunlar bulunmaktadır (Stiglitz, 2010). Yeni Keynesyen iktisatta asimetrik enformasyon, piyasa başarısızlıklarının altında yatan temel nedenlerden birisidir. Asimetrik enformasyon, anlaşmadan önce ve sonra olarak ikiye ayrılmaktadır. Anlaşmadan önceki safhada meydana gelen asimetrik enformasyon problemi ters seçim (adverse selection) sorunu olarak tanımlanmaktadır. Genellikle anlaşma taraflarından birisinin anlaşma öncesi yetersiz bilgiye sahip olmasından kaynaklanmaktadır. Ahlaki risk ise asimetrik enformasyon sorununa dayalı ve işlem sonrasında oluşan bir piyasa başarısızığı olarak tanımlanmaktadır. Ahlaki risk, piyasalarda borç alan tarafin kredi amacının dışında, muhtemelen risk taşıyan ve borç veren tarafindan istenmeyen işlemler yapması olarak tanımlanmaktadır (Mishkin, 1996: 3).Kredi alanların ex ante (işlem öncesi) bireysel enformasyonu ile yüksek risk grubu içerisinde olması ve kendilerini düşük risk grubunda yer alan bireyler gibi göstermesi finansal piyasalarda ahlaki riskin baş göstermesine neden olmaktadır (Barro,1990'dan akt: Hung ve Lee, 2010: 63).

Yeni Keynesyen iktisatta temsili iktisadi ajan (identical agent) yaklaşımı altında tahmin edilen modeller altında finansal kriz yaklaşımında da tutarsızlıklar meydana gelmektedir. Yeni Keynesyen iktisatçılar tarafından sıkça kullanılan Dinamik Stokastik Genel Denge (DSGD) modelleri de piyasa başarısızlıklarını tahmin etme noktasında oldukça güçlük çekmektedir. DSGD modellerinin en önemli özelliklerinden birisi kısa vadede işgücü ve reel piyasalarda nominal dengesizliklere izin vermesidir (Christiano vd., 
2018). Bu noktada kısa vadeli şokların Yeni Keynesyen modellemelerde finansal krizlere neden olduğu yaklaşımı Yeni Keynesyen DSGD modellerde a la Friedman bir yaklaşımın varlığını göstererek aktif para politikasını kısa vadeli şokları gidermek amacıyla politika aracı olarak görmektedir. Christiano vd. (2018) bu noktada kısa vadeli faiz oranları üzerinden iş çevrimlerine olan müdahale aracının Yeni Keynesyen DSGD modellerinde baskın olduğunu belirtmektedir ${ }^{1}$.

2008 finansal krizinde finansal piyasalarda kısa vadeli nakit ihtiyacı ile ortaya çıkan finansal inovasyonlar ve bu finansal inovasyonlardan kaynaklı bilgi asimetrisinin piyasalara ciddi zararlar verdiği yorumu Yeni Keynesyen çerçevede önemli bir yorumdur. Kredi derecelendirme kuruluşlarının bu durumu kendi çıkarları çerçevesinde kullanması, piyasalarda belirsizlikten kaynaklı belirsizliğin suni olarak giderilmesine neden olmuştur. Bu noktada Yeni Keynesyen iktisatçılar a la Stiglitz bir bilgi asimetrisi analizi sunmaktadır. Asensio (2013) Yeni Keynesyenlerin aşırı deregüle edilmiş piyasalardan kaynaklı bilgi asimetrisi sorunu yaklaşımında bir nebze başarılı olduklarını belirtmektedir. Ancak Asensio (2013)'ya göre finansal krize neden olan yapının Stiglitz (2010) tarafindan ifade edilen tam rekabet piyasası olmayan bir piyasada fazla verilen teşvikler, yatırımcının bilgi asimetrisinden dolayı finansal araçları tam olarak algılayamamasından kaynaklı risklerin neredeyse tamamının yatırımcılara aktarılmasından kaynaklıdır. Bu analizde bu riskler de Yeni Keynesyen iktisat tarafindan dışsal faktörler olarak kabul edilmektedir (detaylı bilgi için bknz. Asensio, 2013).

\subsection{Post Keynesyen İktisatta Finansal Kriz Yaklaşımı}

Post Keynesyen İktisat Okulunda piyasa başarısızlıkları yaklaşımı esas itibariyle geleceğin tahmin edilememesinden yani temel belirsizlik (fundamental uncertainty) yaklaşımından kaynaklanmaktadır. Crotty (2009)'e göre Yeni Keynesyen iktisatçıların analizlerinin temeline oturttukları ancak tam olarak özümseyemedikleri bilgi eksikliği, Post Keynesyen temel belirsizlik yaklaşımında önemli bir yere sahiptir. Post Keynesyen iktisat ile Yeni Keynesyen iktisadi analizler arasındaki en temel ayrımlardan birisi de bilgi eksikliği yaklaşımıdır. Post Keynesyen iktisatta tam belirsizlikten kaynaklı panik ya da rasyonel olmayan tercihler finansal kriz dönemlerini ifade eden iktisadi ajan davranışı olarak ön plana çıkmaktadır (Galbraith, 1993; Minsky, 1992). Post Keynesyen makroiktisadi analizlerde Say Kanunu, etkin piyasa hipotezi ve rasyonel birey yaklaşımı açık bir şekilde reddedilmektedir (Lavoie, 2016). Yeni Klasik iktisatta ise dışsal şok yaklaşımında a priori piyasa başarısızlığı ve belirsizlik yaklaşımları reddedilmektedir (Asensio, 2013).

Post Keynesyen iktisatta belirsizlik yaklaşımında ergodik olmayan zaman yaklaşım son derece önemli bir varsayım olma özelliğindedir. Post Keynesyen iktisatta ergodik olmayan zaman yaklaşımı, temel belirsizlik altında elde edilen bilgiler çerçevesinde karar vermeyi finansal krizlerin temeline alan bir yaklaşımdır. Ergodik olmayan zaman

\footnotetext{
${ }^{1}$ Stiglitz (2017)'e göre finansal krizin DGSD modelleri içerisinde stokastik olan model kısmını yani belirsizliği modelleme aşaması önemli sorunlara sahip olan DSGD modelleri 2008 krizini tahmin etmede oldukça tutarsızdır.
}

yaklaşımında geçmişteki bilgiler, gelecek hakkında tam bilgi vermemektedir. Keynes (1936) Genel Teori'de iktisadi ajanların uzun dönemde yapabilecekleri tahminlerin çoğunluğunda güven düzeylerinin altını çizmektedir. Keynes tarafindan davranışsal temellere dayandırılan bu yaklaşımda temel belirsizlik altında iktisadi ajanların karar vermeleri ve beklentilerinin altının çizilmesinin ana nedenlerinden birisi ergodik olmayan zaman yaklaşımıdır.

Yeni Klasik iktisat okulunda ergodik zaman yaklaşımının geçmişteki tarihi ve konjonktürel olguları göz ardı etmesi, zamanı tekrarlı ve sistematik olaylardan ibaret olarak görmesi ve iktisadi olguları bu çerçevede yorumlaması Post Keynesyen iktisatta ciddi bir eleştiri konusu olmuştur. Bu neden ile Post Keynesyen iktisatta zaman geri döndürülemez bir olgudur (Davidson, 1972; Dunn, 2002; Allsopp, 2006). Dolayısıyla Post Keynesyen iktisatta geçmiş bilgiler vasıtasıyla geleceğin tahmin edilmesi, iktisadi aktiviteler açısından elverişli bir durum olmamaktadır. İktisadi ajanların, a priori tam rekabet piyasasında saf ya da tam bilgi dağılımının oluştuğu ve işlem maliyetinin olmadığ piyasadaki gelişmelerin tümünden haberdar olması, Ortodoks iktisat okullarının yaklaşımında ve ergodik zaman paradigmasında önemli yer tutan bir varsayımdır. Ancak Post Keynesyen yaklaşım, Klasik Dikotomi'yi reddederek belirsizliği ergodik olmayan zaman yaklaşımı ile piyasa başarısızlıklarının temeline oturtmaktadır.

Post Keynesyen iktisat okulunda bireylerin ya da girişimcilerin piyasadaki temel belirsizliğin üstesinden gelebilmesi, piyasada elde edinebildiği bilgiler düzeyindedir. Başka bir deyişle bireyler ya da girişimciler piyasada bilgi elde edebilme kapasitesine göre iktisadi kararlar alabilmektedir (Gezici, 2007). Post Keynesyen iktisatçılara göre piyasalardaki düzensizlik ve bilgi asimetrisi piyasalardaki belirsizlikten kaynaklanmaktadır ve piyasaların temel karakteristik özelliklerinden birisidir. Post Keynesyen iktisatta belirsizlikten kaynaklanan iktisadi ajanların kararları genel itibariyle davranışsal temelli bir analize oturtulmaktadır. Bu noktada Minsky, Keynes, Galbraith ve Davidson'un Post Keynesyen finansal kriz analizine/yaklaşımına katkısı önemli düzeydedir.

Palley (1993)'e göre Keynesyen belirsizlik ve iktisadi ajan davranışı arasındaki ilişkiyi yatırım ve tasarruftaki dinamiklerdeki sapmalara bağlamaktadır. Dolayısıyla Keynesyen iktisadın ilgilendiği ana sorunlardan birisi olan talep bu sapmalardan oldukça ciddi anlamda etkilenmektedir. Efektif talep olarak adlandırılan bu yaklaşımda belirsizliğin rolü oldukça önemlidir. Efektif talep teoreminde firmaların $e x$ ante (beklenen) beklentileri ile ex post (gerçekleşen) beklentileri arasındaki farkın, üretime, işgücüne katılmaya olan doğrudan etkisi geçerlidir. Belirsizlik altında firmaların yatırım kararları ex ante beklentiler ile ex post beklentilere eşit ya da büyük ise firma, ekonomide yatırımına devam edecektir, aksi durumda piyasadan çekilme ya da yatırımını azaltma kararı alacaktır. Bu karar ise doğrudan üretimin azalmasına, talep yetersizliğine ve işsizliğe neden olacaktır. Efektif talep yaklaşımında ex ante beklentiler, belirsizlik koşulları altında risk olgusuna göre belirlenmektedir. Firmaların iktisadi kararları efektif talep teoremine göre Modigliani ve Miller (1958) tarafindan savunulan kesin koşullar altında oluşmamaktadır. Tam rekabet piyasasının olmadığı ve bilgi dağılımının piyasadaki ajanlar tarafından eşit paylaşılmaması, firmaların yöneticilerinin de önemli 
düzeyde karar alma aşamasını etkileyen faktörlerdir. Dolayısıyla, Post Keynesyen makro iktisadi analizde toplam talebin belirlenmesinde belirsizlik ve bu belirsizlik ortamında iktisadi ajanların elde edebildiği bilgiler sonucundaki davranışları önemli bir rol oynamaktadır². Keynes'in efektif talep yaklaşımı belirsizlik nedeni ile kısa dönemlidir ve efektif talebin, ülke ekonomilerindeki istikrarsızlıkları ya da konjonktürel dalgalanmaların anlaşılması açısından Post Keynesyen çerçevede önemli varsayımlardan birisidir.

Jespersen (2009: 111) Yeni Klasik iktisat okulu ile Post Keynesyen iktisat okulu arasındaki farklılıkları aşağıdaki gibi özetlemektedir;

- Yeni Klasik iktisat okulunda tam bilgiye dayalı bir yaklaşım mevcut iken Post Keynesyen iktisat okulunda iktisadi ajanlar belirsizlik altında kararlar almaktadır.

- Yeni Klasik iktisatta makro iktisadi gerçeklik, bireysel kararların bir sonucu olarak görülmektedir. Post Keynesyen iktisatta ise makroiktisadi gerçeklik, belirsizlik ve tam bir bütünlük ${ }^{3}$ ile ilişkilidir.

- Yeni Klasik iktisatta uzun dönemli iyi tanımlanmış bir denge durumu mevcut iken Post Keynesyen iktisatta kesin olmayan uzun dönemli denge mevcuttur.

- Yeni Klasik iktisatta makroekonomik sistem bazı dengesizliklere rağmen kendini dengeye getiren bir yapıya sahiptir. Post Keynesyen iktisatta makroekonomik gelişme için tarihsel gelişim önemli bir belirleyici faktördür.

Wolfson (1996: 448-455), Post Keynesyen iktisat okulunda piyasa başarısızlıklarının temeline temel belirsizliği oturtarak oluşabilecek piyasa başarısızlıklarının altını çizmektedir. Bu piyasa başarısızlıklarından ilki, kredi alıcı ile kredi verenin gelecek beklentilerinin farklı olması (asimetrik beklentiler) sayılmaktadır. Diğer bir piyasa başarısızlığı ise geleceğin belirsizliğinden dolayı kredi veren ve alanın riskleri yani belirsizlik altında kredi reytinglerinin ve bankanın kredi verme isteğinin belirlenmesi ancak gelecekteki öngörülerin muhtemelen gerçekleşmemesi sayılmaktadır. Diğer bir piyasa başarısızlığı ise finansal kırılganlıktır. Finansal kırılganlık, kredi verenin borcunun yükselmesi ve borç vadesinin kısalması ile piyasalarda likiditenin azalması olarak ifade edilmektedir.

Post Keynesyen iktisat okulunda önemli bir iş çevrimi sayılan Hyman Minsky (1992)'e ait finansal istikrarsızlıkhipotezinde Post Keynesyen piyasa başarısızlığı yaklaşımının temel varsayımlarını görmek mümkündür. Minsky (1992), finansal

${ }^{2}$ Keynes(1936) efektif talep teoremindeki yaklaşımı; Z(Toplam arz)'nin $\mathrm{N}$ sayıda kişinin istihdamı sonucu oluşan arz fiyatı; $\mathrm{Z}=\varnothing \mathrm{N}$, $\mathrm{D}$ ise $\mathrm{N}$ sayıda kişinin istihdamı sonucu girişimcinin elde edeceği gelir $\mathrm{D}=f(\mathrm{~N})$ olarak ifade etmektedir. $\mathrm{D}$ ile Z'nin kesiştiği nokta ise efektif talep noktası olarak adlandırılmaktadır. Bu noktada Post Keynesyen makro iktisadi analizde talep odaklı yaşanan sıkıntılar beraberinde işsizlik ve arzda ciddi daralmaları da beraberinde getirmekte ve finansal krizin reel sektörden kaynaklı nedenlerine öncülük etmektedir. Kriz zamanlarında arz azalması sonucu işsizliğin artması olgusu efektif talep teoremi vasıtası ile daha iyi anlaşılmaktadır.

3 Burada kast edilen tam bütünlük yaklaşımı bireyin toplum içerisindeki rolü, toplumsal olgulardan etkilenmesi gibi varsayımlara sahip olan ve metodolojik bireyciliği reddeden organiklik yaklaşımına dayanmaktadır (Doruk, 2011). istikrarsızlık hipotezi yaklaşımının temeline kar beklentilerini Kaleckiyen çerçevede oturtarak, istikrarsızlıkta oluşabilecek sıkıntıların kar beklentileri ve borç düzeyleri arasındaki gelişmelere bağlı olduğunu belirtmektedir. Kar beklentileri, yatırımcı için bir anlamda belirsizlikten kaynaklı sorunları gidermek için güvenli bir liman olarak görülmektedir. Nitekim Minsky (1992)'nin analizinde iş çevrimlerini ortaya çıkaran olgular karlılık ve borç arasındaki ilişkilere dayanmaktadır. Minsky (1992)'nin yaklaşımında kapitalist bir ekonomide istikrarsızlıkların temel belirsizlik altında istikrarsız olacağı varsayımı yapılmaktadır. Böyle bir varsayımın altında yatan ana neden ise iktisadi ajanların davranışlarıdır. Belirsizlik altında iktisadi ajanların euphoria ${ }^{4}$ dönemine bağlı olarak optimist yaklaşımları iş çevrimini oluşturmaktadır (Minsky, 1992; Keen, 2013).

Post Keynesyen iktisatta finansal piyasalardaki iktisadi ajan davranışı Post Keynesyen iktisadın kurumsalcılık (institutionalist) yaklaşımında daha çok davranışsal kökenlere inen bir yapıya sahiptir (daha detaylı bilgi için bknz. Davidson, 2007; Dow, 2008).

Davidson (2002) iktisadi ajanların piyasalarda belirsizlik altında finansal varlık tutma eğiliminde olduğunu belirtmektedir. İyi organize olmuş finansal piyasalarda iktisadi ajanlar bu varlığ herhangi bir belirsizlik durumunda hızlı çıkış stratejisi amacıyla kullanmakta ve bu strateji hızlı varlık satışlarına neden olmaktadır. $\mathrm{Bu}$ yaklaşım banka iflaslarını (bank runs) ya da ani varlık satışlarını (fire asset sales) tetikleyerek finansal krizlere neden olabilmektedir. Dolayısıyla bu belirsizlik finansal piyasalarda varlık fiyatlarında ciddi azalmalara neden olmaktadir ${ }^{5}$.

\section{2001 Finansal Krizinin Post Keynesyen Analizi}

Türkiye ekonomisinde yaşanılan 2001 finansal krizi, genelde finansal piyasalarda özelde bankacılık sektöründe başlayıp daha sonrasında tüm ekonomiyi kontrol altına alan bir yapıdadır. 2001 finansal krizi sonrasında önemli banka birleşmeleri, Tasarruf Mevduatı ve Sigorta Fonu (TMSF), Bankacılık Denetleme ve Düzenleme Kurumu (BDDK) gibi finansal regülatörlerin kurulması ile bankacılık sektörünün sağlam bir yapıya kavuştuğu görülmektedir. 2001 finansal krizinin incelenmesi bakımından çalışmada reel sektördeki belirsizlik-yatırımlar ve iş çevrimi ilişkisi kullanılarak Post Keynesyen çerçevede 2001 finansal krizi incelenmektedir. Özellikle gelişmekte olan ve geç sanayileşen bir ülke konumunda olan Türkiye ekonomisi için yatırımların büyüme ve kalkınma açısından uzun vadeli kritik durumu, kısa vadede iş çevrimlerinin derinleşmesi açısından oldukça önemlidir.

Post Keynesyen çerçevede Türkiye'de yaşanılan 2001 finansal krizinin incelenmesi açısından GSYİH içerisinde zirve (peak) ve ani düşme (turning) noktalarının tespit edilmesi gerekmektedir. Çalışmada bu noktaların tespiti açısından Harding ve Pagan (2002) yöntemi kullanılmıştır. Harding ve Pagan (2002) tarafindan kullanılan yöntem, iş çevrimlerinde (ya da finansal kriz hesaplamalarında) Okun

${ }^{4}$ Euphoria dönemleri, Minsky (1992)'nin iş çevrimlerinde önemli bir yer tutan, iktisadi ajanların beklentilerini iyimserlik altında oldukça iyimser tuttuğu dönemler olarak tanımlanmaktadır.

${ }^{5} 2008$ finansal krizinin temelinde ani varlık satışlarının yer aldığını literatürde önemli düzeyde yer alan bir varsayımdır. Detaylı bilgi için bknz. Gorton (2010). 
tarafından iki çeyrek negatif büyüme oranının saptanması vasitasıyla resesyon dönemlerinin tespit edilmesine dayanmaktadir. Harding ve Pagan (2002) tarafindan kullanılan yöntemde zirve durumları $\{\Delta y \mathrm{t}>0, \Delta y \mathrm{t}+1<0$, $\Delta \mathrm{yt}+2<0\}$ durumunda; ani düşme dönemleri ise $\{\Delta \mathrm{yt}<0$, $\Delta y \mathrm{t}+1>0, \Delta \mathrm{yt}+2>0\}$ olarak belirlenmektedir. Harding ve Pagan (2002)'in yöntemi, Amerika Ulusal Ekonomi Araştırmaları Bürosu (NBER-National Bureau of Economic Research) ve Bry ve Boschan (1971) 'a dayanmaktadır. Bu yöntem, iş çevrimi hesaplamasında kırpma yöntemine dayalı olarak bu noktaları elde etmektedir. Şekil 1'de GSYİH'nın ani düşme noktaları içerisinde açıkça 2001 finansal krizinin yaşandığı dönemlerin de yer aldığı görülmektedir.

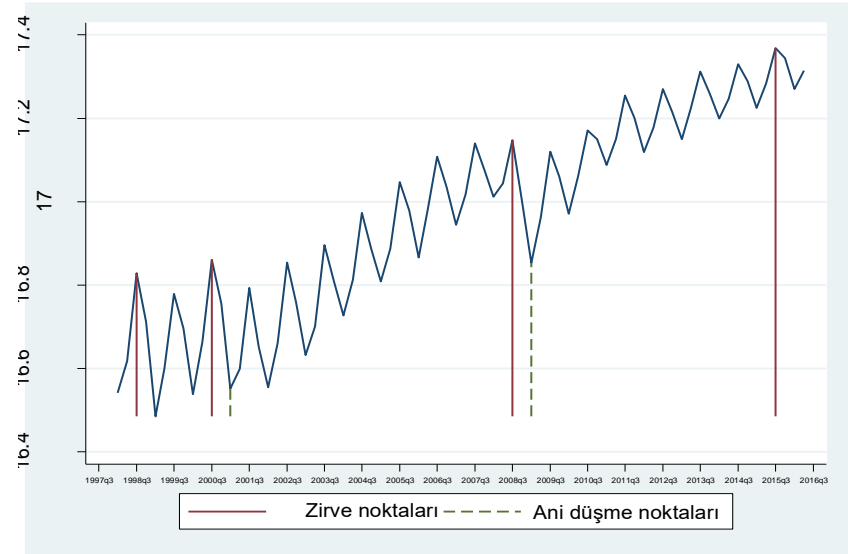

Kaynak: Yazar tarafindan TCMB EVDS(2018) verileri kullanılarak hesaplanmıştır.

Şekil 1. GSYİH için Harding ve Pagan (2002) Yöntemi’ne dayalı zirve ve ani düşme noktaları, reel GSYİH, 1998Q1 2016Q2

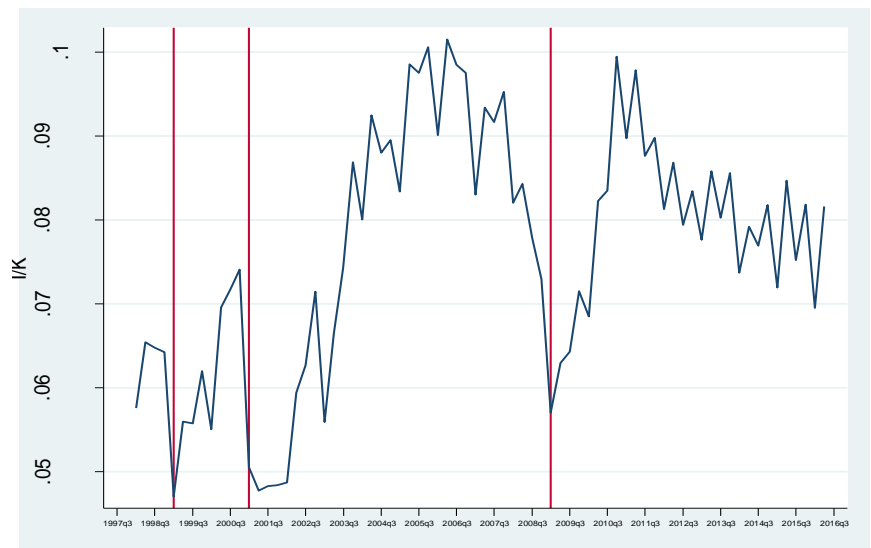

Kaynak: Yatırım oranı, yazar tarafindan TCMB EVDS(2018) verileri kullanılarak hesaplanmıştır. Yatırım oranı yatırımların sermaye stokuna bölünmesiyle elde edilmiştir. Sermaye stoku; doğrusal envanter yöntemine göre hesaplanmıștır (Aşınma oranını ifade eden $\delta=\% 7$ olarak alınmıştır. Sağlamlık kontrolü için \%5 alınsa da sonuçlar arasında çok az fark olduğu görülmektedir. Tüm sonuçlar yazardan istenilebilir.) Kırmızı çizgiler, Şekil 1'de yer alan ani düşme noktalarını göstermektedir.

Şekil 2. Yatırım oranının GSYİH'nın ani düşme noktalarındaki gelişimi, 1998Q1-2016Q2, reel
Şekil 2'de yatırım oranının iş çevrimlerinin ani düşme noktalarındaki gelişimi görülmektedir. Bu noktada yatırım oranının Post Keynesyen iktisatçıların da ifade ettiği gibi iş çevrimlerinin ani düşme noktalarında azaldığı görülmektedir. Özellikle Türkiye'de yaşanılan 2001 finansal krizinin Post Keynesyen çerçevede açıklamasının başarılı bir açıklama olduğu görülmektedir. Şekil 3'te yer alan belirsizlik hesaplamaları da bu çerçeveyi doğrulamaktadır.

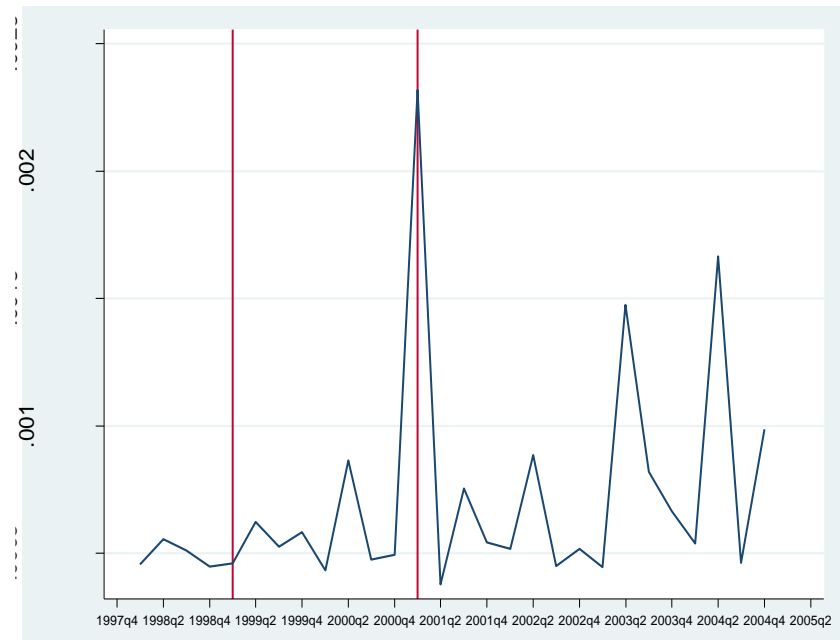

Kaynak: Koşullu varyans, yazar tarafindan TCMB EVDS(2018) verileri kullanılarak hesaplanmıştır. Hesaplama aşamasında aylık olarak alınan toptan sanayi fiyatları endeksinin büyüme oranının GARCH $(1,1)$ hesaplaması sonucunda elde edilen koşullu varyansın üçer aylık ortalaması, uygulamalı literatürde sıkça kullanıldığı üzere belirsizliğin temsili değişkeni (proxy) olarak kullanılmıştır. Çalışmanın analiz kısmının 2001 finansal krizinin Türkiye için araştırılması olduğundan serinin 2004 yılsonunda bitmesi üzerine grafikte 2009 krizi raporlanmamıştır. Kırmızı çizgiler, Şekil 1'de yer alan ani düşme noktalarını göstermektedir.

Şekil 3. Belirsizlik oranının ani düşme noktalarındaki gelişimi, 1998Q1-2004Q4

Şekil 1, Şekil 2 ve Şekil 3'te yer alan hesaplamalar özetlenecek olursa, belirsizlik altında yatırımların azalması ve iş çevriminin ani düşme noktasına ulaşması aynı çeyrek içerisinde yaşanılarak, bir anlamda 2001 finansal krizinin Türkiye ekonomisinde yaşandığ açıklamasını yatırım kanalı üzerinden yapan bir sonuca ulaşılmıştır.

\section{Sonuc}

Finansal kriz yaklaşımı, son yaşanan 2008 finansal krizinin tahmin edilememesinden kaynaklı olarak Lavoie (2016) tarafından da vurgulandığı üzere makro iktisatta bir kriz ortaya çıkarmıştır. Bu neden ile çalışmada finansal kriz yaklaşımı, Post Keynesyen, Yeni Klasikler ve Yeni Keynesyen makro iktisadi analiz ile karşılaştırmalı olarak analiz edilmektedir. Post Keynesyen makroiktisadi analizde piyasa başarısızlıkların temelinde belirsizlik ve iktisadi ajanların davranışları temelinde yer alırken Yeni Klasik ve Yeni Keynesyen iktisatta temsili ve rasyonel iktisadi ajan temelinde dışsal bir finansal kriz yaklaşımı bulunmaktadır. 
Bu çalışma, iktisat okullarının finansal krizlere yaklaşımını karşılaştırmalı olarak analiz edilmesinin yanı sıra Türkiye ekonomisi için 2001 finansal krizinin açıklanmasında Post Keynesyen iktisadın daha başarılı bir açıklama gücüne sahip olduğu sonucuna ulaşılmıştır. Belirsizlik altında Türkiye'de 2001 finansal krizinin yatırımların azalmasıyla birlikte oldukça ciddi bir iş çevrimine neden olduğu görülmektedir.

$\mathrm{Bu}$ çalışma özet olarak finansal krizleri açıklamada son dönemde makro iktisadın da kendi krizini yaşadığı bir dönemde Post Keynesyen iktisat okulunun 2001 finansal krizinde Türkiye ekonomisini açıklamasının altını çizmektedir. Çalışmada elde edilen sonuçlar özetlenecek olursa Post Keynesyen iktisatta finansal kriz yaklaşımında tam belirsizlik altında finansal sorunların reel sektördeki göstergelere sıçraması Klasik Dikotomi'nin reddine dayanan bir yaklaşımın ön plana çıkmasına neden olmaktadır. Türkiye'de yaşanılan 2001 finansal krizinin ise belirsizlik ve bu belirsizlikten kaynaklı sorunların yatırımlar kanalından oldukça ciddi bir iş çevrimine neden olduğu ve bu döngünün Post Keynesyen çerçevede açıklanmasının oldukça makul olduğu sonucuna ulaşılmıştır. Türkiye'de yaşanılan 2001 finansal krizini açıklama açısından Post Keynesyen iktisadın göreli olarak diğer iktisat okullarına göre daha başarılı bir alternatif olduğu yorumlanabilir.

\section{Kaynakça}

Allsopp, V. (2002). Trust, Time and Uncertainty. İçinde: S.C. Dow \& J. Hillard (Ed.) Post Keynesian Econometrics, Microeconomics and the Theory of the Firm (s.81-96), Cheltenham: Edward Elgar Publishing.

Asensio, A. (2013). The Achilles' Heel Of The Mainstream Explanations of the Crisis and a Post Keynesian Alternative. Journal of Post Keynesian Economics, 36 (2), 355-380.

Bry, G. \& Boschan, C. (1971).Cyclical Analysis of Time Series: Selected Procedures and Computer Programs. NBER: New York.

Crotty, J. (2009).Structural Causes of the Global Financial Crisis: A Critical Assessment of the 'New Financial Architecture'.Cambridge Journal of Economics, 33 (4), 563-580.

Christiano, L.J; Eichenbaum, M.S. ve Trabandt, M. (2018). On DSGE Models. Journal of Economic Perspectives, 32 (3), 113-140.

Davidson, P. (1972).Money and the Real World, London: Macmillan.

Davidson, P. (2002). Financial Markets, Money and the Real World. Cheltenham: Edward Elgar.

Davidson, P. (2007). John Maynard Keynes. Palgrave Macmillan: Basingstoke.

Doruk, Ö. T. (2011) .Post Keynezyen İktisadi Birey ve Post Keynezyen İktisat Metodolojisinde Krizlerin Dinamikleri Üzerine Yazınsal Bir İnceleme: 1929 ve 2008 Krizi Karşılaştırması. İçinde:İ. Şiriner., F. Morady, J. Mika, M. Aydın, Ş.A., H. Kapucu, ve E. Doğan (Ed.) Politik İtisat, Kriz ve Kalkınma (s.87-106). Londra: IJOPEC Publication.
Dow, S. (2008). Mainstream Methodology, Financial Markets, and Global Political Economy. Contributions to Political Economy, 27(1), 13-29.

Dunn, S.P. (2002). A Post Keynesian Approach to the Theory of the Firm. İçinde: S.C. Dow \& J. Hillard (Ed.) Post Keynesian Econometrics, Microeconomics and the Theory of the Firm (s.60-80), Cheltenham: Edward Elgar Publishing.

Galbraith, J.K.(1993).A Short History of Financial Euphoria. Houghton Mifflin:Boston.

Gezici, A. (2007). Investment under Financial Liberalization: Channels of Liquidity and Uncertainty. Ph.D. Dissertation, University of Massachusetts Amherst.

Gorton, G. (2010). E-coli, Repo Madness, and the Financial Crisis.Business Economics, 45(3), 164-173.

Hung, F.-S.\& Lee, C.-C. (2010).Asymmetric Information, Government Fiscal Policies, And Financial Development.Economic Development Quarterly, 24(1), 60-73

Jespersen, J. (2009). Macroeconomic Methodology A PostKeynesian Perspective. Edward Elgar: Cheltenham

Johnson, L.E; Ley,R., \& Cate, T. (2001).Keynes' Theory of Money and His Attack on the Classical Model. International Advances in Economic Research, 7 (4), 409418.

Keen, S. (2013). Predicting the 'Global Financial Crisis': Post-Keynesian Macroeconomics. Economic Record, 89(285), 228-254.

Keynes, J. M. (1936). The General Theory of Money, Interest and Employment. London: Macmillan

Lavoie, M. (2016). Understanding the Global Financial Crisis: Contributions of Post-Keynesian Economics.Studies in Political Economy, 97, 58-75.

Minsky, H. P.(1992).The Financial Instability Hypothesis. Levy Institute Çalışma Tebliği no. 74.

Mishkin,F. S.(1996). Understanding Financial Crises : A Developing Country Perspective. NBER Çalışma Tebliği no.5600

Modigliani, F. \& Miller, M. H. (1958).The Cost of Capital, Corporation Finance and the Theory of Investment.The American Economic Review, 48 (3), 261-297.

Palley, T.I. (1993). Uncertainty, Expectations, and the Future: If We Don't Know the Answers, What Are the Questions? Journal of Post Keynesian Economics, 16(1),3-18.

Romer, D. (1993). The New Keynesian Synthesis.The Journal of Economic Perspectives, 7 (1), 5-22

Stiglitz, J. (2010). Risk and Global Economic Architecture: Why Full Financial Integration may be Undesirable. NBER Çalışma Tebliği no. 15718.

Stiglitz, J. (2017). Where Modern Macroeconomics Went Wrong. (Erişim: 08.11.2018)

https://www.ineteconomics.org/uploads/papers/WhereModern-Macroeconomics-Went-Wrong.pdf 
Wecker, W. (1979). Predicting the Turning Points of a Time Series.Journal of Business, 52, 35-50.

Wolfson, M. H. (1996). A Post Keynesian Theory of Credit Rationing.Journal of Post Keynesian Economics, 18(3),443-470. 
